\title{
Correction to: Interest Consistency Can Buffer the Effect of COVID-19 Fear on Psychological Distress
}

\section{Akihiro Masuyama $^{1} \cdot$ Takahiro Kubo $^{2} \cdot$ Daichi Sugawara $^{3} \cdot$ Yuta Chishima $^{3}$}

Published online: 28 June 2021

(C) Springer Science+Business Media, LLC, part of Springer Nature 2021

\section{Correction to: International Journal of Mental Health and Addiction https://doi.org/10.1007/s11469-021-00564-5}

The name of coauthor Yuta Chishima was presented incorrectly (as Chishima Yuta) in this article as originally published.

The original article has been corrected.

Publisher's Note Springer Nature remains neutral with regard to jurisdictional claims in published maps and institutional affiliations.

The online version of the original article can be found at https://doi.org/10.1007/s11469-021-00564-5

\author{
Akihiro Masuyama \\ ak.masuyama@gmail.com \\ Takahiro Kubo \\ songyou312@gmail.com \\ Daichi Sugawara \\ sugawara@human.tsukuba.ac.jp \\ Yuta Chishima \\ chishimay@gmail.com
}

1 Faculty of Psychology, Iryo Sosei University, Chuodai-Iino 5-5-1, Iwaki City, Fukushima 970-8551, Japan

2 Psychological Counseling Center, Iryo Sosei University, Chuodai-Iino 5-5-1, Iwaki City, Fukushima 970-8551, Japan

3 Faculty of Human Sciences, University of Tsukuba, Tennodai 1-1-1, Tsukuba, Ibaraki, Japan 